\title{
Long-Term Prognostic Factors in Patients with Significant Left Main Coronary Artery Disease
}

\author{
Mercedes Camprubí, Ramón de Castro, Mohsen Mohandes, Jordi Guarinos, \\ Miriam Garcia-Bermúdez, Alfredo Bardají* \\ Servicio de Cardiología, Hospital Universitario de Tarragona Joan XXIII, Pere Virgili Institute for Health Research, \\ Universitat Rovira Virgili, Tarragona, Spain \\ Email: *abardaji@comt.es
}

Received 23 December 2013; revised 22 January 2014; accepted 20 February 2014

Copyright (C) 2014 by authors and Scientific Research Publishing Inc.

This work is licensed under the Creative Commons Attribution International License (CC BY). http://creativecommons.org/licenses/by/4.0/

\section{Open Access}

\begin{abstract}
Introduction and Objectives: The natural history of patients with left main coronary artery disease (LMCAD) is largely unknown. Our objective was to analyse the predictors of long-term mortality in these patients, both those that have had surgery and those that have not undergone surgery for various reasons, in a cohort treated at a university hospital. Methods: The study included patients with significant LMCAD diagnosed through consecutive coronary angiograms from 2001 to 2009. Clinical variables, the reasons for cardiac catheterisation, therapeutic decisions and clinical evolution in long-term follow-up were analysed. Results: Of the 163 patients included in the analysis, a total of $109(66.9 \%)$ underwent revascularisation, while the remaining $54(33.1 \%)$ received other medical treatment. We analysed the clinical events that took place with a mean follow-up period of 54 months (IQR: 25 - 95). The non-revascularised group had a lower survival rate than the revascularised group in unadjusted analysis (logrank test 0.005). Age (OR 1.04, CI 1.02 - 1.07, p $=0.001$ ), ventricular dysfunction (OR 2.87 , CI95\% 1.71 - 4.81, $p<0.0001)$, clinical instability (OR $2.11, \mathrm{CI} 95 \% 1.08$ to $4.13, \mathrm{p}=\mathbf{0 . 0 2 8}$ ) and above $70 \%$ severity of LMCAD (OR 1.78, CI 1.09 to $2.91, \mathrm{p}$ $=0.021$ ) were independent predictors of mortality for the entire cohort, but revascularisation was not. Conclusions: Revascularisation is associated with improved survival in patients with LMCAD, but only age, ventricular dysfunction, clinical instability and the severity of the lesion are independent predictors of long-term mortality in the unselected population.
\end{abstract}

\section{Keywords}

Left Main Coronary Artery Disease; Surgical Revascularisation; Percutaneous Coronary Intervention

\footnotetext{
${ }^{*}$ Corresponding author.
}

How to cite this paper: Camprubí, M., de Castro, R., Mohandes, M., Guarinos, J., Garcia-Bermúdez, M. and Bardají, A. (2014) Long-Term Prognostic Factors in Patients with Significant Left Main Coronary Artery Disease. International Journal of Clinical Medicine, 5, 188-196. http://dx.doi.org/10.4236/ijcm.2014.55032 


\section{Introduction}

Due to its high mortality, according to current European and American guidelines for clinical practice [1] [2], the recommended procedure for improving the prognosis of patients with significant LMCAD is surgical revascularisation (SR). Although SR continues to be the leading method of treatment, it cannot always be used for various reasons such as high risk, poor coronary anatomy, advanced age and comorbidity, among others. In patients where SR is contraindicated, percutaneous coronary intervention (PCI) is a good alternative, as numerous studies comparing SR and PCI of the LMCAD [3]-[5] have shown. Complex anatomy or contraindication for dual antiplatelet therapy as well as other factors may also preclude treating patients by means of this method, leaving medical treatment as the only option. This means that in daily clinical practice, a certain percentage of patients with LMCAD do not undergo revascularisation and can only choose medical treatment [6] [7]. The current natural history of patients with LMCAD without revascularisation is not well known, as current research series examining the outcomes of surgical [8] or percutaneous [9]-[12] treatments do not cover the evolution of non-revascularised patients. Furthermore, today patients with ischemic heart disease are generally treated with pharmacological measures that are associated with a better prognosis. The real benefit of revascularisation compared to medical therapy must be understood, while taking into account that the clinical profile of these two groups of patients is usually different.

Our goal is to understand the impact of revascularisation in patients with LMCAD in an unselected sample, evaluating long-term survival and the subgroups that benefit most from the treatment, while considering the clinical and angiographic factors that influence the decision for percutaneous or revascularisation surgery.

\section{Patients and Methods}

\subsection{Study Design and Population}

We conducted an observational study of a retrospective cohort in which the initial reference population was 4851 consecutive patients from our immediate healthcare population who underwent coronary angiography in our hospital from 2001 to 2009. Our study population consisted of patients with newly diagnosed LMCAD (stenosis $>50 \%$ ). Patients with significant associated valvular disease, or a history of previous heart surgery were excluded.

The following variables were obtained in a review of clinical records: age, sex, cardiovascular risk factors (diabetes, dyslipidemia, tobacco use, hypertension, family history of early-onset heart disease); history of cardiovascular disease (angina, myocardial infarction, heart failure, stroke or peripheral arterial disease); coronary angiography recommendation (scheduled elective or due to acute coronary syndrome or pulmonary oedema) and its result. The degree of stenosis of the LMCAD and the rest of the coronary anatomy was assessed by quantitative comparative analysis (QCA). The coronary angiography recommendation was attributed to clinical instability when requested in the context of an acute coronary syndrome or acute pulmonary oedema. LMCAD lesions were considered significant when the stenosis quantified exceeded $50 \%$ of the diameter of the artery, and severe LMCAD was defined as stenosis greater than $70 \%$. Reduced ejection fraction $(<50 \%)$ or normal ejection fraction were also noted. Clinical follow-up was performed in outpatient care, by phone or by review of computerised medical records. The events recorded during follow-up were cardiovascular death or death due to any other cause.

\subsection{Statistical Analysis}

The quantitative continuous variables with Gaussian distribution are described as mean \pm standard deviation (SD), whereas those that do not follow that distribution according to the Kolmogorov-Smirnov test are shown as median and interquartile range (IQR). Categorical variables are described as frequencies. The episode-free survival curve was generated using the Kaplan-Meier estimator. To study whether there were differences in the distribution of clinical, demographic and angiographic variables in revascularised and medically treated patients, univariate analysis was conducted for quantitative variables using the student's t-test for independent samples and the nonparametric U Mann-Whitney test based on whether the sample distribution was normal or not. Categorical variables were compared between groups with the chi [2] test. To determine the factors associated with the mortality of these patients, we conducted a univariate analysis using Cox proportional hazards. Lastly, to independently determine predictors associated with mortality in the patients, a multivariate Cox proportional haz- 
ards analysis was performed using backward stepwise elimination (with an input value $<0.05$ and a p value of output $>0.1$ ). Variables that were distributed differently between the revascularised and medically treated groups as well as variables significantly associated with mortality in the univariate analysis and variables considered clinically relevant were included. Specifically, these included the following: age, sex, history of hypertension, diabetes mellitus, tobacco smoking, previous myocardial infarction, heart failure, reduced ejection fraction, instability, LMCAD above $70 \%$ and revascularisation. Possible interaction between the resulting variables of the final model was assessed using the chunk test, with absence of interaction considered to be $p>0.05$. The results are presented as hazard ratios (HR) with confidence intervals of 95\% (95\% CI) and p values set at a level of statistical significance of $p<0.05$. We performed a post hoc analysis of a set of variables to understand the unadjusted hazard risks for the benefit of revascularisation over medical therapy in specific subgroups of patients. Statistical analyses were conducted using the SPSS 15.0 statistics program for Windows (SPSS, Inc., Chicago, Illinois, USA).

\section{Results}

Of the 4851 consecutive coronary angiograms conducted from 2001 to 2009, we found 211 new diagnoses of LMCAD (stenosis > 50\%), representing 4.3\%. Of these, 46 patients were excluded due to previous coronary or valvular surgery or associated valvular disease, and two patients were excluded due to lack of follow-up. The study group consisted of 163 patients of whom 101 (62\%) were revascularised with coronary surgery and eight (5\%) by means of percutaneous coronary intervention. The remaining 54 patients (33\%) were dismissed from any type of revascularisation, opting initially for medical treatment. The main reasons for dismissal from surgical revascularisation were distal beds unsuitable for surgery (47.1\%); the presence of comorbidities (46.3\%) such as severe lung disease; history of recent neurological vascular events; advanced age; peripheral artery disease and obesity; hemodynamic instability or shock including sepsis (4.7\%); and patient refusal (1.9\%).

The distinguishing characteristics between patients who were revascularised (surgically or percutaneously) and non-revascularised patients are shown in Table 1 . The revascularised patients were significantly younger and included a higher proportion of men and current smokers, less history of myocardial infarction and heart failure, and a greater proportion of severe LMCAD, although with a lower proportion of three-vessel disease compared to patients who were not revascularised.

During an average follow up of 57 months (IQR: 32 - 98) revascularised patients had a cumulative incidence of mortality of $33 \%$, with $68.6 \%$ due to cardiovascular causes compared to a cumulative incidence of mortality of $57.4 \%$ in patients who were not revascularised, with a median follow-up of 42 months (IQR: 17 - 92), of which $67.7 \%$ were due to cardiovascular causes HR: 0.51 (0.32 - 0.92), $p=0.006$ (Figure 1).

\section{Predictors of Mortality}

In an unadjusted analysis, the difference in the survival curves of revascularised and non-revascularised patients were statistically significant (logrank test $\mathrm{p}=0.004$ ) (Figure 1, Table 2). After adjusted analysis, the variables independently associated with mortality were age HR: 1.04 (1.02 to 1.07), $\mathrm{p}=0.001$; ventricular dysfunction HR: 2.87 (1.71 to 4.81), $\mathrm{p}=0.001$; clinical instability HR: 2.11 (1.09 to 4.13), $\mathrm{p}=0.028$; and LMCAD severity exceeding 70\% HR: $1.79(1.09-2.91), p=0.021$ (Table 3). No interaction was found between the variables of the final model (chunk test $\mathrm{p}>0.05$ ). Unadjusted hazard ratios for mortality related to revascularisation therapy and medical treatment in different subgroups of patients of clinical interest are shown in Figure 2. When two or more categorical independent variables are selected for mortality (ventricular dysfunction, clinical instability and diagnosis of severe LMCAD), the survival curve of patients who received intervention were clearly more favourable than that of patients with no intervention. In contrast, the group of patients who had only one or no related variables showed no significant benefit in terms of mortality with revascularisation (Figure 3).

\section{Discussion}

Our study demonstrates that coronary revascularisation in patients with LMCAD is associated with improved prognosis in unadjusted analysis. However, the prognosis actually depends primarily on patient comorbidity influenced by age, ventricular function, clinical instability at the time of diagnosis, and the severity of the 
Table 1. Demographic characteristics, risk factors, history and angiographic data of medically treated and revascularised patients.

\begin{tabular}{|c|c|c|c|}
\hline & Medical therapy $(n=54)$ & Revascularisation $(\mathrm{n}=109)$ & $\mathrm{p}$ \\
\hline Age (average \pm SD) & $72.2 \pm 9.8$ & $64.6 \pm 10.7$ & 0.001 \\
\hline Sex, female (\%) & 33.3 & 19.3 & 0.048 \\
\hline Diabetes (\%) & 46.3 & 40.4 & 0.471 \\
\hline Dyslipidemia (\%) & 61.8 & 62 & 0.909 \\
\hline Arterial hypertension (\%) & 68.5 & 63.4 & 0.559 \\
\hline Smoking & & & 0.001 \\
\hline Active & 11.1 & 22.9 & \\
\hline Ex-smoker & 24.1 & 43.6 & \\
\hline No & 64.8 & 33.9 & \\
\hline Obesity (\%) & 18.5 & 25.7 & 0.308 \\
\hline History of MI (\%) & 46.3 & 25.7 & 0.008 \\
\hline History of angina (\%) & 53.7 & 41.3 & 0.134 \\
\hline Family history of HF (\%) & 5.7 & 7.3 & 0.690 \\
\hline History of stroke (\%) & 1.9 & 4.6 & 0.383 \\
\hline History of IC (\%) & 18.5 & 6.4 & 0.017 \\
\hline Peripheral artery disease (\%) & 22.2 & 14.7 & 0.229 \\
\hline Reduced EF (\%) & 31.5 & 22 & 0.190 \\
\hline Severity of LMCAD & & & 0.239 \\
\hline $\mathrm{CT}>90 \%$ & 9.3 & 17.4 & \\
\hline CT: 71\% - 90\% & 18.5 & 22.9 & \\
\hline CT: $50-70$ & 72.2 & 59.6 & \\
\hline Clinical instability (\%) & 74.1 & 71.6 & 0.735 \\
\hline Associated vessels & & & 0.012 \\
\hline 3 vessels & 66.7 & 41.3 & \\
\hline 2 vessels & 22.2 & 30.3 & \\
\hline 1 vessel & 9.3 & 17.4 & \\
\hline 0 vessels & 1.9 & 11 & \\
\hline
\end{tabular}

SD: standard deviation, MI: myocardial infarction, IC: ischemic cardiopathy, HF: heart failure, EF: ejection fraction, LMCAD: left main coronary artery disease.

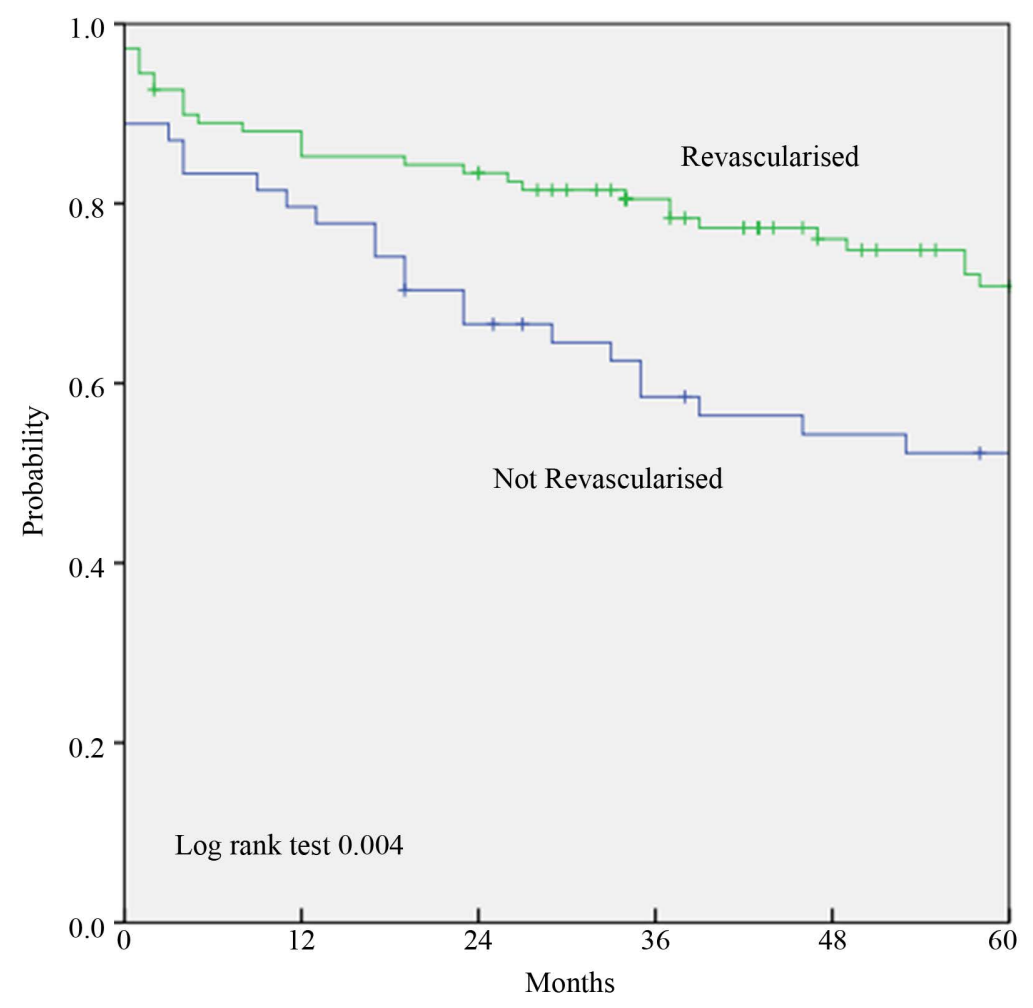

Figure 1. Survival curves for revascularised and non-revascularised patients. 
Table 2. Predictors of mortality in univariate analysis.

\begin{tabular}{ccc}
\hline & HR $(95 \% \mathrm{CI})$ & $\mathrm{p}$ \\
\hline Age & $1.04(1.01-1.06)$ & 0.004 \\
Sex, female & $0.97(0.54-1.72)$ & 0.908 \\
Diabetes & $0.94(0.58-1.53)$ & 0.802 \\
Hypertension & $1.04(0.63-1.73)$ & 0.868 \\
Tobacco use & $1.07(0.78-1.46)$ & 0.683 \\
Previous infarction & $1.04(0.62-1.73)$ & 0.885 \\
Peripheral artery disease & $1.55(0.84-2.83)$ & 0.160 \\
History of ischemic cardiopathy & $3.01(1.67-5.45)$ & 0.000 \\
Number of vessels & $3.01(1.67-5.45)$ & 0.013 \\
Reduced EF & $2.95(1.79-4.87)$ & 0.000 \\
Clinical instability & $2.83(1.47-5.43)$ & 0.002 \\
Severity of LMCAD $>70 \%$ & $1.54(0.95-2.49)$ & 0.080 \\
Revascularisation & $0.51(0.32-0.92)$ & 0.006 \\
\hline
\end{tabular}

HR: hazard ratio, CI: confidence interval, HF: heart failure, EF: ejection fraction, LMCAD: left main coronary artery disease.

Table 3. Predictors of mortality in multivariate analysis.

\begin{tabular}{ccccc}
\hline & & & & \\
& HR & CI & & \\
Age & 1.04 & $1.02-1.07$ & 0.001 & \\
Reduced EF & 2.87 & $1.71-4.81$ & 0.0001 \\
Clinical instability & 2.11 & $1.09-4.13$ & 0.028 \\
LMCAD lesion $>70 \%$ & 1.79 & $1.09-2.91$ & 0.021 \\
\hline
\end{tabular}

HR: hazard ratio, CI: confidence interval, EF: ejection fraction, LMCAD: left main coronary artery disease.

LMCAD lesion.

\subsection{Revascularisation in LMCAD}

Clinical practice guidelines on revascularisation in patients with LMCAD lesions equal to or greater than $50 \%$ stipulate that coronary surgery has a Class I indication regardless of the severity of the lesion and the clinical status of the patient [1]. The indication for revascularisation of the LMCAD is mainly based on a meta-analysis of four small studies and three medium-sized studies conducted in patients with stable angina in the 70s who were randomly selected for surgical revascularisation or medical treatment as an initial strategy [13]. We would like to note two considerations: firstly, of the 2649 patients included in this study only 150 (6.6\%) had LMCAD; and secondly, medical treatment consisted only of administrating beta-blockers (in 66\% of patients), occasionally the administration of aspirin (18.8\%), without using statins or angiotensin-converting-enzyme inhibitors. This meta-analysis showed a benefit for revascularisation at five years of follow-up ( $\mathrm{RR}=0.32,95 \% \mathrm{CI}$ : 0.15 to $0.70, \mathrm{p}=0.005)$, but this was lost at 10 years $(\mathrm{RR}=0.67,95 \% \mathrm{CI} 0.35-1.3$, $\mathrm{p}=0.24)$.

An important breakthrough in the treatment of LMCAD was the advent of PCI, which has become an excellent alternative since the introduction of the stent. The SYNTAX [14] study compared the effect of SR and PCI with drug-eluting stents in three-vessel disease and LMCAD, demonstrating that mortality and stroke rates after the procedure were similar with both techniques. The rate of stroke was higher in the surgical revascularisation group, whereas the need for repeat revascularisation was higher in the PCI group.

\subsection{Clinical Instability and Severity of LMCAD}

Two clinical conditions merit special attention. Firstly, we have found that patient clinical instability is a factor associated with greater revascularisation benefit. In other words, stable patients do not seem to benefit from revascularisation to the same degree. There is a paucity of current data on the need for revascularisation in stable patients. In fact, the CASS registry on LMCAD only has data for 53 asymptomatic patients compared to a total sample of 1477 that were virtually all symptomatic [15]. The prognosis for clinically stable patients was reported to be positive (annual event rate: 2.8\%) for patients with LMCAD and/or three-vessel disease [16]. This positive prognosis would be difficult to improve on with any surgical or percutaneous revascularisation tech- 


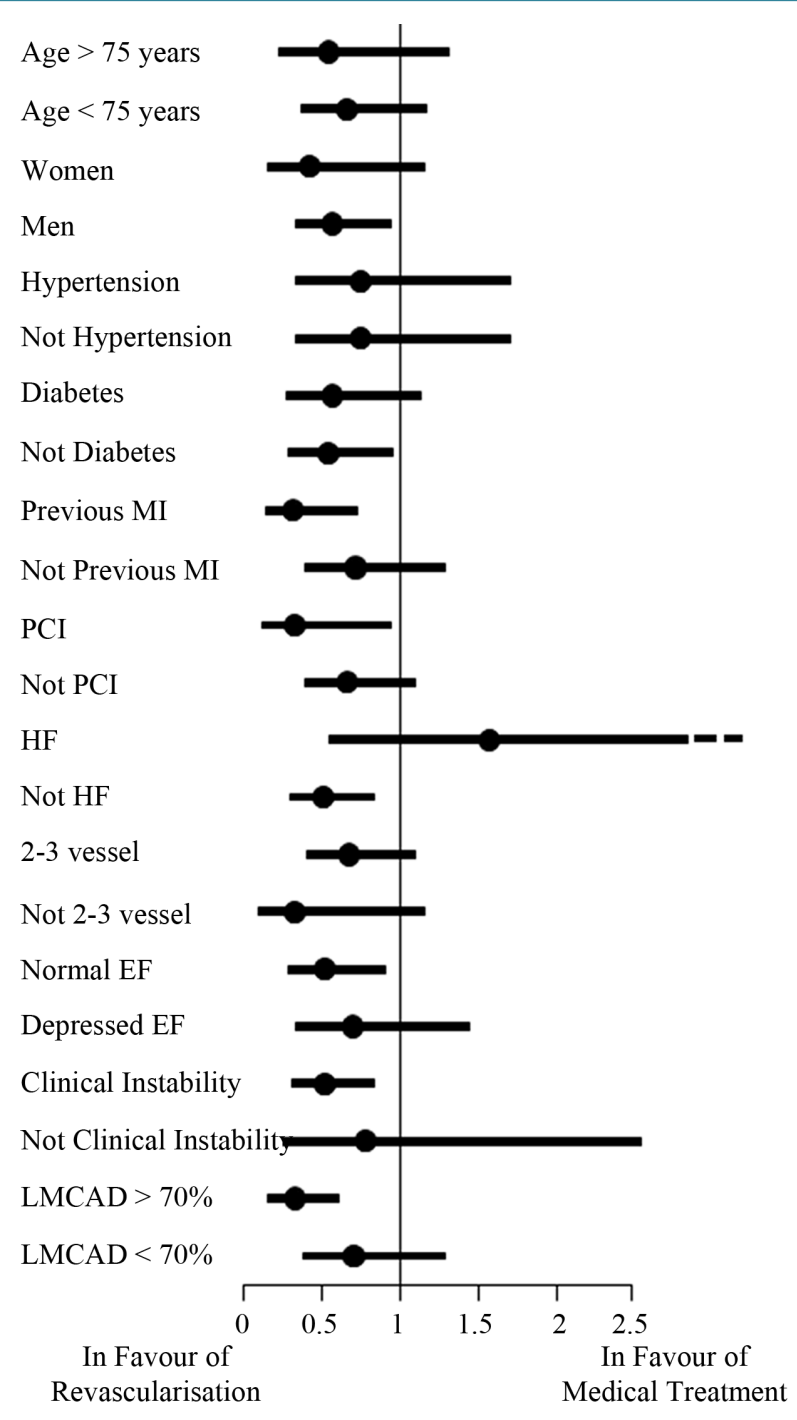

Figure 2. Effect of revascularisation versus medical therapy (HR with 95\% according logrank test) according to patient subgroup. MI: myocardial infarction, PCI: percutaneous coronary intervention, HF: heart failure, EF: ejection fraction, LMCAD: left main coronary artery disease.

nique. Secondly, the severity of LMCAD lesions is another aspect that should be taken into consideration. We found that patients with lesions greater than $70 \%$ benefit from revascularisation, whereas there is some doubt about the efficacy of revascularisation in lesions between $50 \%-70 \%$. Again, this is poorly defined in the literature. In a sub-analysis of the veterans series [17], 91 patients had lesions between $50 \%$ and $75 \%$ and the benefit of revascularisation could not be demonstrated $(p=0.089)$. In the CASS registry, the benefit for the subgroup of patients with lesions of 50\% to 59\% [18] could not be demonstrated. Traditionally the argument for revascularisation of LMCAD has been the elevated risk for the patient in event of plaque complications or acute occlusion. However, the risk of plaque rupture and acute coronary syndrome in the evolution of patients with coronary artery disease is not well documented. There is evidence that patients with LMCAD lesions below 50\% actually run a slight risk of rupture without excess mortality at seven years (HR $0.98,95 \%$ CI 0.79 to 1.23 ) [19]. The hazard of lesions between $50 \%$ and $70 \%$ is unknown, but if we consider that most acute coronary syndromes are caused by less severe plaques, then the risk should not be excessively greater than in patients with less severe lesions, and we know that the prognosis will be good.

It is well known that coronary angiography has limitations in terms of quantifying the severity of LMCAD le- 

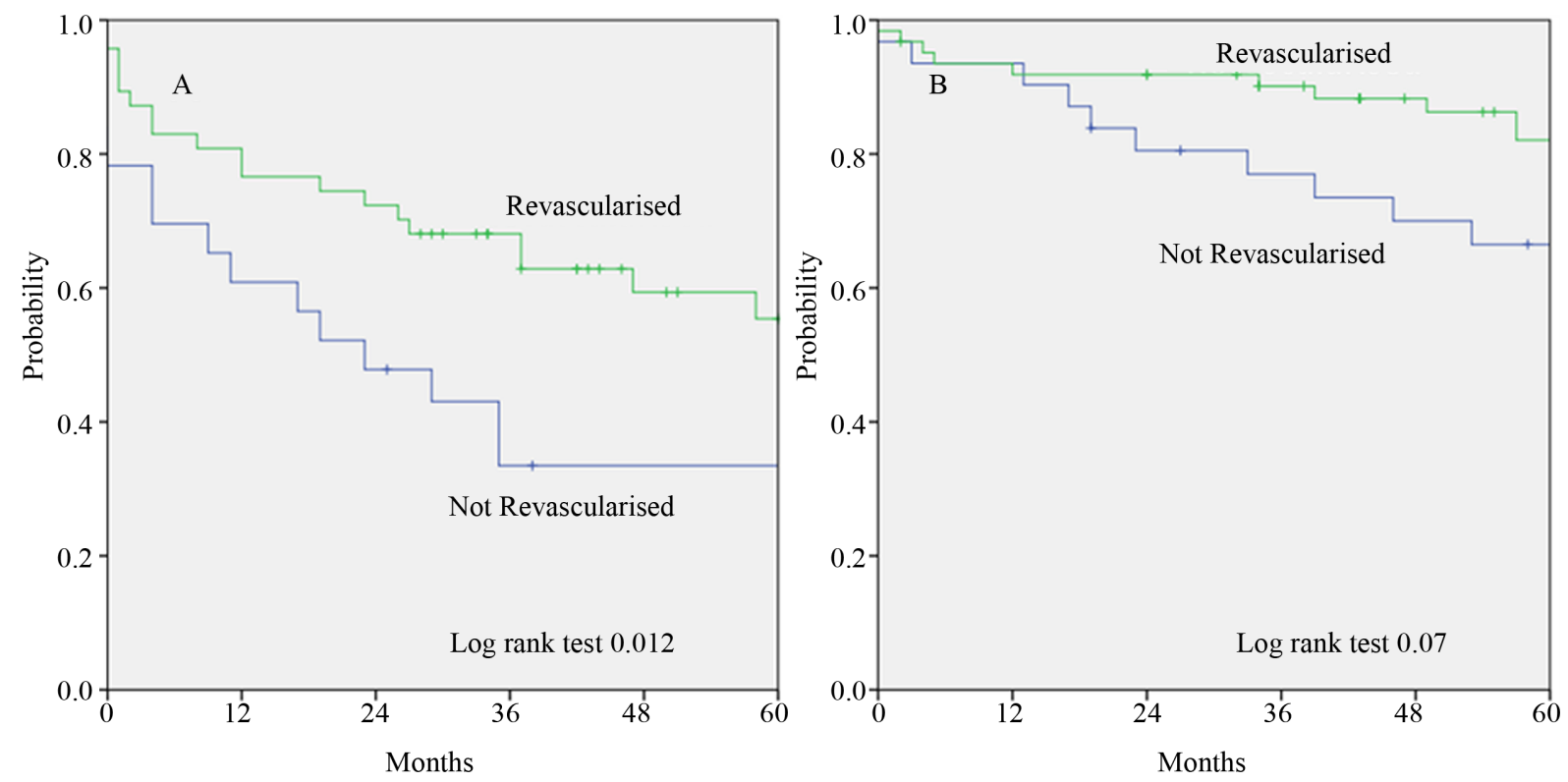

Figure 3. (A) Survival curves for revascularised and non-revascularised subjects in the group of patients with two or more predictors of mortality (including ventricular dysfunction, clinical instability, and LMCAD with severity greater than $70 \%$ ); (B) Survival curves for revascularised and non-revascularised subjects in the group of patients without two or more predictors of mortality (including ventricular dysfunction, clinical instability, and LMCAD with severity greater than 70\%).

sions. However, the assessment of fractional flow reserve in these patients with a cut-off value of less than 0.75 for opting for revascularisation also failed to show differences between revascularised and non-revascularised patients in a follow-up of 38 months [20]. Despite these data, growing importance has been placed on quantifying coronary artery threshold lesion values [21], because in the real world lesions with a luminal area greater than $6 \mathrm{~mm}$ [2] are not uncommon.

\subsection{Changes in the Prognosis of LMCAD}

We believe that one of the factors that could explain our results are advances in the pharmacological treatment of LMCAD. The last 30 years have seen remarkable progress in secondary prevention and the benefit of surgery for patients with LMCAD, on par with the benefit from statins in secondary prevention, for example. The 4S study with simvastatin in patients with stable ischemic heart disease found a relative risk reduction of $30 \%$ in terms of mortality [22]. Current high-dose statins induce a relative reduction in risk in both non-revascularised and revascularised patients [23]. But statins are not alone in altering the natural history of patients with ischemic heart disease: the nearly systematic use of aspirin and, on many occasions, angiotensin-converting-enzyme inhibitors for ventricular dysfunction, heart failure and diabetes is changing the natural history of revascularised as well as non-revascularised patients [24].

Patients with LMCAD are currently selected for surgical revascularisation or PCI based on surgical risk, clinical characteristics and patient preferences, with a cumulative mortality of $25.2 \%$ at three years [6] [7], but there are no data on the characteristics or follow-up of patients who do not receive revascularisation. In light of this, our study underscores the poor prognosis of patients who do not undergo revascularisation, of which more than half die within three years after diagnosis. Therefore, we believe that before making the decision for or against revascularisation for patients with LMCAD, clinical variables such as age, ventricular function, clinical instability at the time of diagnosis, and severity of the lesion of coronary artery should be should taken into consideration in addition to presenting a significant LMCAD, as these factors may influence patient prognosis.

\subsection{Limitations}

Our study has several limitations that should be emphasised. It is an observational study based on data obtained from a retrospective cohort with a limited number of variables for the analysis of results. Most patients were 
treated with revascularisation surgery and fewer with PCI. Although PCI is gaining prominence in our field, during the period in which patients were included in the study, several studies also showed concern for the negative prognosis of patients treated with PCI in the medium-term [9]-[11].

Another limitation of the study, which began in 2001, is that Euroscores were not available for all patients. We should mention that the dismissal of the case for revascularisation was made by medical consensus in a joint session. Comorbidity and poor distal vessels were the most frequent reasons for not performing surgery.

Finally, we do not know the exact medical treatment used in revascularized and not revascularized patients, but we do not think than medical treatment was significant different between groups.

\section{Conclusion}

In our series, we observed that surgical revascularisation or PCI in selected cases is indicated for most patients with significant LMCAD, especially in the event of clinical instability, ventricular dysfunction or severe LMCAD lesion. In the absence of these conditions, the indication for revascularisation should be considered, with data from other revascularised and non-revascularised patient series with long-term follow-up. These series are highly recommended for comparison with our results and in order to define the minimum and maximum group benefit of revascularisation in patients with LMCAD.

\section{References}

[1] Task Force on Myocardial Revascularization of the European Society of Cardiology (ESC), The European Association for Cardio-Thoracic Surgery (EACTS) and European Association for Percutaneous Cardiovascular Interventions (EAPCI) (2010) Guidelines on Myocardial Revascularization. European Heart Journal, 31, 2501-2555. http://dx.doi.org/10.1093/eurheartj/ehq277

[2] Hillis, L.D., et al. (2011) 2011 ACCF/AHA Guideline for Coronary Artery Bypass Graft Surgery: Executive Summary: A Report of the American College of Cardiology Foundation/American Heart Association Task Force on Practice Guidelines. Circulation, 124, 2610-2642. http://dx.doi.org/10.1161/CIR.0b013e31823b5fee

[3] Chakravarty, T., Buch, M.H., Naik, H., White, A.J., Doctor, N., Schapira, J., et al. (2011) Predictive Accuracy of SYNTAX Score for Predicting Long-Term Outcomes of Unprotected Left Main Coronary Artery Revascularization. American Journal of Cardiology, 107, 360-366. http://dx.doi.org/10.1016/j.amjcard.2010.09.029

[4] Kim, Y.H., Park, D.W., Kim, W.J., Lee, J.Y., Yun, S.C., Kang, S.J., Lee, S.W., Lee, C.W., Park, S.W. and Park, S.J. (2010) Validation of SYNTAX (Synergy between PCI with TAXUS and Cardiac Surgery) Score for Prediction of Outcomes after Unprotected Left Main Coronary Revascularization. JACC Cardiovascular Interventions, 3, $612-623$. http://dx.doi.org/10.1016/j.jcin.2010.04.004

[5] Serruys, P. and Garg, S. (2009) Percutaneous Coronary Interventions for All Patients with Complex Coronary Artery Disease: Triple Vessel Disease or Left Main Coronary Artery Disease. Yes? No? Don’t Know? Revista Española de Cardiología, 62, 719-725. http://dx.doi.org/10.1016/S0300-8932(09)71683-5

[6] De Lorenzo, A., Tura, B., Bassan, F., Pittella, F. and Rocha, A.S. (2011) Outcomes of Patients with Left Main Coronary Artery Disease Undergoing Medical or Surgical Treatment: A Propensity-Matched Analysis. Coronary Artery Disease, 22, 585-589. http://dx.doi.org/10.1097/MCA.0b013e32834c7501

[7] Gziut, A., Gil, R. and Kulawik, T. (2010) Comparative Analysis of Conservative, Percutaneous, and Surgical Treatment Outcomes in Patients with Significant Stenosis of the Left Main Coronary Artery during Five-Year Follow-Up. Kardiologia Polska, 68, 381-390.

[8] Gan, H.L., Zhang, J.Q., Bo, P., Wang, S.X. and Lu, C.S. (2010) Statins Decrease Adverse Outcomes in Coronary Artery Bypass for Extensive Coronary Artery Disease As Well As Left Main Coronary Stenosis. Cardiovascular Therapeutics, 28, 70-79. http://dx.doi.org/10.1111/j.1755-5922.2009.00098.x

[9] Martí, V., Planas, F., Cotes, C., García, J., Guiteras, P., López, L. and Augé, J.M. (2004) Resultados Inmediatos y a Largo Plazo de la Angioplastia con stent del Tronco Común. Revista Española de Cardiología, 57, 1029-1034. http://dx.doi.org/10.1016/S0300-8932(04)77238-3

[10] Gomez-Hospital, J.A., Gomez-Lara, J., Rondan, J., Homs, S., Lozano Martınez-Luengas, I., Ferreiro, J.L., Roura, G., Maristany, J., Teruel, L., Carro, A., Avanzas, P., Jara, P., Esplugas, E., Moris, Z. and Cequier, A. (2012) Seguimiento a Largo Plazo tras el Tratamiento Percutáneo del Tronco Coronario Izquierdo no Protegido en Pacientes de Alto Riesgo no Aptos para Cirugía de Revascularización. Revista Española de Cardiología, 65, 530-537.

http://dx.doi.org/10.1016/j.recesp.2011.12.020

[11] López-Palop, R., Pinar, E., Saura, D., Pérez-Lorente, F., Lozano, I., Teruel, F., et al. (2004) Resultados a Corto y 
Medio Plazo del Intervencionismo Coronario Percutáneo Sobre el Tronco Coronario Común Izquierdo no Protegido en Pacientes Malos Candidatos para Revascularización Quirúrgica. Revista Española de Cardiología, 57, 1035-1044. http://dx.doi.org/10.1016/S0300-8932(04)77239-5

[12] Ielasi, A., Latib, A., Chieffo, A., Takagi, K., Mussardo, M., Davidavicius, G., et al. (2013) Very Long-Term Outcomes Following Drug-Eluting Stent Implantation for Unprotected Left Main Coronary Artery Stenosis: A Single Center Experience. Revista Española de Cardiología, 66, 24-33. http://dx.doi.org/10.1016/j.recesp.2012.06.026

[13] Yusuf, S., Zucker, D., Peduzzi, P., Fisher, L.D., Takaro, T., Kennedy, J.W., et al. (1994) Effect of Coronary Artery Bypass Graft Surgery on Survival: Overview of 10-Year Results from Randomised Trials by the Coronary Artery Bypass Graft Surgery Trialists Collaboration. Lancet, 344, 563-570. http://dx.doi.org/10.1016/S0140-6736(94)91963-1

[14] Serruys, P.W., Morice, M.C., Kappetein, A.P., Colombo, A., Holmes, D.R., Mack, M.J., et al. (2009) Percutaneous Coronary Intervention versus Coronary-Artery Bypass Grafting for Severe Coronary Artery Disease. New England Journal of Medicine, 360, 961-972. http://dx.doi.org/10.1056/NEJMoa0804626

[15] Taylor, H.A., Deumite, N.J., Chaitman, B.R., Davis, K.B., Killip, T. and Rogers, W.J. (1989) Asymptomatic Left Main Coronary Artery Disease in the Coronary Artery Surgery Study (CASS) Registry. Circulation, 79, 1171-1179. http://dx.doi.org/10.1161/01.CIR.79.6.1171

[16] Amanullah, A.M., Heo, J., Acio, E., Narula, J. and Iskandrian, A.E. (1999) Predictors of Outcome of Medically Treated Patients with Left Main/Three-Vessel Coronary Artery Disease by Coronary Angiography. American Journal of Cardiology, 83, 445-448. http://dx.doi.org/10.1016/S0002-9149(98)00883-2

[17] Takaro, T., Peduzzi, P., Detre, K.M., Hultgren, H.N., Murphy, M.L., van der Bel-Kahn, J., et al. (1982) Survival in Subgroups of Patients with Left Main Coronary Artery Disease. Veterans Administration Cooperative Study of Surgery for Coronary Arterial Occlusive Disease. Circulation, 66, 14-22. http://dx.doi.org/10.1161/01.CIR.66.1.14

[18] Caracciolo, E.A., Davis, K.B., Sopko, G., Kaiser, G.C., Corley, S.D., Schaff, H., et al. (1995) Comparison of Surgical and Medical Group Survival in Patients with Left Main Coronary Artery Disease. Long-Term CASS Experience. Circulation, 91, 2325-2334. http://dx.doi.org/10.1161/01.CIR.91.9.2325

[19] Gyenes, G., Shrive, F.M., Graham, M.M., Ghali, W.A. and Knudtson, M.L. (2006) APPROACH Investigators. The Prognostic Importance of Nonsignificant Left Main Coronary Artery Disease in Patients Undergoing Percutaneous Coronary Intervention. Journal of the American College of Cardiology, 48, 276-280. http://dx.doi.org/10.1016/j.jacc.2006.02.067

[20] (1994) Randomised Trial of Cholesterol Lowering in 4444 Patients with Coronary Heart Disease: The Scandinavian Simvastatin Survival Study (4S). Lancet, 344, 1383-1389.

[21] Gan, H.L., Zhang, J.Q., Bo, P., Wang, S.X. and Lu, C.S. (2010) Statins Decrease Adverse Outcomes in Coronary Artery Bypass for Extensive Coronary Artery Disease As Well As Left Main Coronary Stenosis. Cardiovascular Therapeutics, 28, 70-79. http://dx.doi.org/10.1111/j.1755-5922.2009.00098.x

[22] Diaz-Buschmann, I., Castro, A., Galve, E., Calero, M.J., Dalmau, R., Guzmán, R., et al. (2012) Comentarios a la Guía de Práctica Clínica de la ESC Sobre Prevención de la Enfermedad Cardiovascular (Versión 2012). Un informe del Grupo de Trabajo del Comité de Guías de Práctica Clínica de la Sociedad Española de Cardiología. Revista Española de Cardiología, 65, 869-873. http://dx.doi.org/10.1016/j.recesp.2012.08.001

[23] Jasti, V., Ivan, E., Yalamanchili, V., Wongpraparut, N. and Leesar, M.A. (2004) Correlations between Fractional Flow Reserve and Intravascular Ultrasound in Patients with an Ambiguous Left Main Coronary Artery Stenosis. Circulation, 110, 2831-2836. http://dx.doi.org/10.1161/01.CIR.0000146338.62813.E7

[24] Sano, K., Mintz, G.S., Carlier, S.G., de Ribamar Costa Jr, J., Qian, J., Missel, E., et al. (2007) Assessing Intermediate Left Main Coronary Lesions Using Intravascular Ultrasound. American Heart Journal, 154, 983-988. http://dx.doi.org/10.1016/j.ahj.2007.07.001

\footnotetext{
Abbreviations

LMCAD = left main coronary artery disease

$\mathrm{SR}=$ surgical revascularisation

$\mathrm{PCI}=$ percutaneous coronary intervention

$\mathrm{CI}=$ confidence interval

$\mathrm{OR}=$ odds ratio
} 